\title{
Effect of the blade number on the marine propeller performance
}

\author{
Fatima Bouregba ${ }^{1,}$ a, Mustapha Belkadi ${ }^{1}$, Mohammed Aounallah ${ }^{1}$, Lahouari Adjlout $^{1}$ \\ ${ }^{1}$ Laboratory of Aero-Hydrodynamics Naval, University of Sciences and Technology of Oran-Mohamed Boudiaf, \\ P.O. 1505El-Mnaouar Oran, Algeria.
}

\begin{abstract}
This paper deals with numerical simulation of stationary flow around a marine propeller. The aim is to reproduce the hydrodynamic turbulent flow around the Wageningen B serie propellers in open water using the ANSYS FLUENT code and the RANS approach. The computational domain consists of an inter-blade channel with periodic boundaries, meshed with tetrahedral cells. The turbulence is modeled with the $\mathrm{k}-\omega$. The obtained results provide good agreement with the available experimental data and show that the blades number affects considerably the marine propellers performances. It is interesting to notice that the six blades propeller is the best adapted one for the open water flows.
\end{abstract}

keywords: Marine propeller, Wageningen B series, CFD simulation, RANS

\section{Introduction}

The performance of marine propellers is nowadays an interesting topic of investigation for scientific research devoted to the development of marine technologies. To improve the performance of the propeller, it is essential to increase their efficiency defined by the ratio that links the thrust to the torque. The flow around the propeller is very complex and the resolution of governing equations requires the use of increasingly efficient approaches. Among researchers that contributed to the marine propellers improvements we must mention Arazgaldi et al. [1] who presented a numerical investigation using a cavitation and non-cavitating model to determine hydrodynamic characteristics of two propellers with three and four blades propellers respectively. The cavitation was calculated and the obtained numerical results were compared with the experimental ones adopted by the K23 cavitation tunnel at the Sharif University of Technology. The comparison study showed a fairly good agreement. Krasilnikov et al. [2] studied the effect of the skew angle on the propeller characteristics, three propellers were considered with several skew angles. It was concluded that the increasing of the skew angle leads to a relative decrease of torque at heavier loadings. Watanabe et al. [3] applied unstructured grid technique to the flow around the Sieun-maru propeller. The agreement with experiment is good for steady and unsteady conditions. S.E. Belhenniche et al [4] investigated the effect of geometric configurations on hydrodynamic performance of marine propeller, their parametric study has allowed achieving optimal shape factors ensuring best hydrodynamic performances. Later H.Ghassemi et al [5] used the potential Boundary Element Method (BEM) to study the influence of the ship wake and the skew on the conventional Seiun Maru (CP) and highly skewed HSP

${ }^{\mathrm{a} C}$ Corresponding author: fatimabouregba@hotmail.com fatima.bouregba@univ-usto.dz
Seiun Maru propellers performances. The employed method demonstrates that for a lower skew, the total thrust and torque for the (CP) marine propellers give larger fluctuations than HSP. A multiobjective optimization method is employed by Benini [6] for the Wageningen B propeller series using an algorithm for maximizing the efficiency and thrust coefficients under a constraint determined according to cavitation.

In the present study, a numerical investigation of the influence of the blades number on the hydrodynamic performances of the propeller has been performed. The propellers studied belong to the B series witch which are one of the commonly used series as a benchmark for their abundant experimental data [7]. Many simulations were carried out to get the optimum propeller geometry by variation of blades number (4, 5 and 6 blades). The Reynolds number based on the blade diameter is equal to $2.10^{6}$ and the advance coefficient varies from 0.3 to 0.7 .

\section{Geometry}

To generate the propeller geometry, a FORTRAN program has been developed to provide the spatial points coordinates for different cross sections according to the data given in table 1 . The obtained points coordinates are then exported to the pre-processor GAMBIT, and are connected with spline lines. Surfaces are generated by connecting lines and then the volume of the blade is created. The shaft is connected to the propeller root blade using the T-junction technique. 
Table 1. Main geometrical characteristics of the profiles for four, five, six and seven blades, [7].

\begin{tabular}{|c|c|c|c|c|c|}
\hline \multirow{2}{*}{$r / R$} & \multirow{2}{*}{$\frac{C}{D} \frac{Z}{A_{E} / A_{0}}$} & \multirow{2}{*}{$a / c$} & \multirow{2}{*}{$b / c$} & \multicolumn{2}{|c|}{$t / D=A_{r}-B_{r} Z$} \\
\hline & & & & $\mathrm{A}_{r}$ & $\mathrm{~B}_{r}$ \\
\hline 0.2 & 1.662 & 0.617 & 0.350 & 0.0526 & 0.0040 \\
\hline 0.3 & 1.882 & 0.613 & 0.350 & 0.0464 & 0.0035 \\
\hline 0.4 & 2.050 & 0.601 & 0.351 & 0.0402 & 0.0030 \\
\hline 0.5 & 2.152 & 0.586 & 0.355 & 0.0340 & 0.0025 \\
\hline 0.6 & 2.187 & 0.561 & 0.389 & 0.0278 & 0.0020 \\
\hline 0.7 & 2.144 & 0.524 & 0.443 & 0.0216 & 0.0015 \\
\hline 0.8 & 1.970 & 0.463 & 0.479 & 0.0154 & 0.0010 \\
\hline 0.9 & 1.582 & 0.351 & 0.500 & 0.0092 & 0.0005 \\
\hline 1.0 & 0.000 & 0.000 & 0.000 & 0.0030 & 0.0000 \\
\hline
\end{tabular}

$\mathrm{A}_{r}, \mathrm{~B}_{r}$ : constants in equation for $t / D$.

$a$ : distance between leading edge and generator line at $r$. $b$ : distance between leading edge and location of maximum thickness.

$c$ : chord length of blade section at radius $r$.

$t$ : maximum blade section thickness at radius $r$.

Figure 1 presents the 3D geometries of three generated propellers characterized by the same expanded area ratio $\mathrm{A}_{\mathrm{E}} / \mathrm{A}_{0}=0.75$, similar pitch ratio $\mathrm{P} / \mathrm{D}=0.8$ and different blade number $(Z=4,5,6)$.

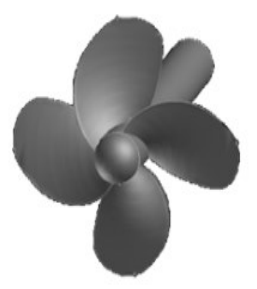

$\mathrm{Z}=4$

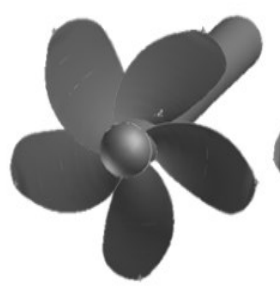

$Z=5$

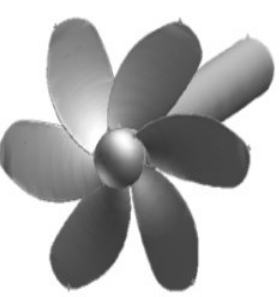

$\mathrm{Z}=6$
Fig. 1. Blade shape and propeller geometry

\section{Modelisation}

The incompressible turbulent viscous flow field around submerged propeller is simulated with Reynolds Averaged Navier-Stokes (RANS) equations. The governing equations expressing the conservation of masse and momentum are written as follows:

$$
\begin{aligned}
& \frac{\partial U_{i}}{\partial x_{i}}=0 \\
& \frac{D U_{i}}{D t}=-\frac{1}{\rho} \frac{\partial p}{\partial x_{i}}+\frac{\partial}{\partial x_{j}}\left[\left(v+v_{t}\right) \frac{\partial v_{i}}{\partial x_{j}}\right] \quad i=1,3
\end{aligned}
$$

where $\mathrm{U}_{\mathrm{i}}$ is the averaged velocity, $P$ is the averaged pressure, $\rho$ is the density, $v$ is the dynamic viscosity.
The turbulence is modeled using the $k \omega$ model. This model is believed to be one of the best choices to simulate turbulence flow around propellers. The governing equations of this model are as follows, [12]:

$$
\begin{aligned}
& \frac{\partial \kappa}{\partial t}+U_{j} \frac{\partial \kappa}{\partial x_{j}}=\tau_{i j} \frac{\partial U_{i}}{\partial x_{j}}-\beta^{*} \kappa \omega+\frac{\partial}{\partial x_{j}}\left[\left(\nu+\sigma^{*} v_{T}\right) \frac{\partial \kappa}{\partial x_{j}}\right] \\
& \frac{\partial \omega}{\partial t}+U_{j} \frac{\partial \omega}{\partial x_{j}}=\alpha \frac{\omega}{k} \tau_{i j} \frac{\partial u_{i}}{\partial x_{j}}-\beta \omega^{2}+\frac{\partial}{\partial x_{j}}\left[\left(\mu+\sigma \mu_{T}\right) \frac{\partial \omega}{\partial x_{j}}\right]
\end{aligned}
$$

The turbulent viscosity is defined as follows:

$$
\mu_{t}=\frac{K}{\omega}
$$

The standard wall function of Launder and Spalding is used [13].

\section{Numerical procedure}

All numerical simulations were carried out by the code FLUENT. The flow is considered stationary. For the coupling the SIMPLE algorithm solver is selected to solve the pressure and momentum equations which can lead to a more robust calculation and faster convergence. The discritization schemes adopt QUIK for momentum quantity, STANDARD type for the pressure and UPWIND for turbulent kinetic energy and the specific dissipation of turbulent kinetic energy.

In order to reduce the mesh size, a steady simulation is carried out using the rotational periodic and the calculation domain is represented by a channel with a single blade. The inlet boundary is set at $1.5 \mathrm{D}$ with a uniform inflow depending on the advance coefficient $J$ The outlet is fixed at $3.5 \mathrm{D}$ with a static pressure condition and the outer boundary is at $1.4 D$ from the shaft axis $[10$, 11]. The slip condition is set for the top outer boundary while the adherence condition is imposed for the blade and hub surfaces. The fluid is considered rotational around the shaft axis by using the Moving Reference Frame (MRF) option.

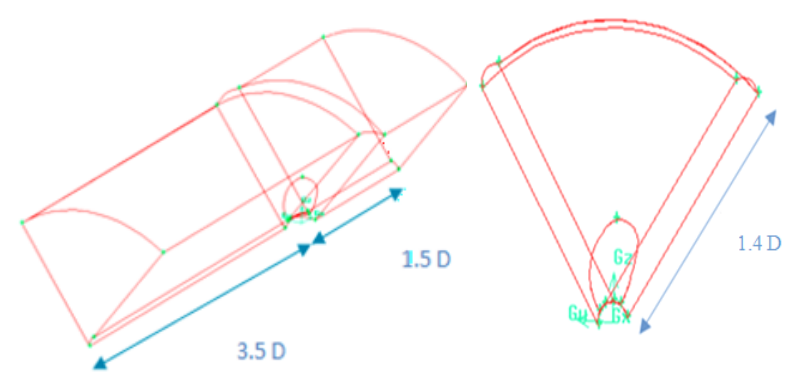

Fig. 2. Periodic computational domain

For the mesh generation, the Gambit pro-processor has been used. The shape and the mesh number influence 
directly the accuracy of iterative process and precision of results.

The numerical domain is meshed by tetrahedral meshes as shown in figure 3. Four meshes were generated and tested of the propeller model as resumed in table 2 .

Table 2.Mesh characteristics

\begin{tabular}{|c|c|c|c|c|}
\hline Mesh & $\begin{array}{c}\text { Element } \\
\text { number }\end{array}$ & $\begin{array}{c}\text { Blade } \\
\text { element } \\
\text { size }\end{array}$ & $\begin{array}{c}\text { Shaft } \\
\text { element } \\
\text { size }\end{array}$ & $\begin{array}{c}\text { Other } \\
\text { surfaces } \\
\text { element } \\
\text { size }\end{array}$ \\
\hline 01 & 800.000 & 0.030 & 0.039 & 0.077 \\
\hline 02 & 1.200 .000 & 0.025 & 0.035 & 0.067 \\
\hline 03 & 1.600 .000 & 0.020 & 0.029 & 0.060 \\
\hline 04 & 2.000 .000 & 0.018 & 0.019 & 0.0585 \\
\hline
\end{tabular}

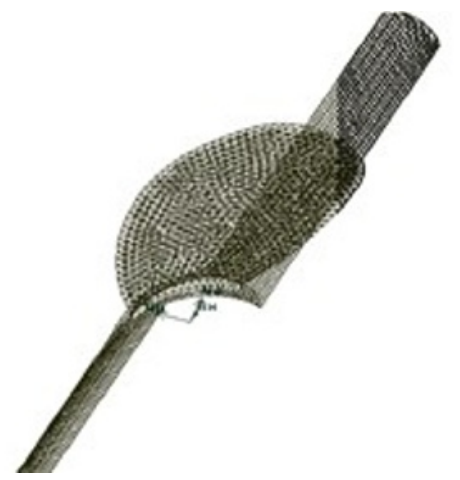

Figure 3.Blade and shaft tetrahedral mesh

\section{Results and discussion}

The numerical simulations are performed for three blade numbers namely B4-75, B5-75 and B5-75. For all the calculations, the Reynolds number based on the blade diameter is $2.10^{6}$ and the coefficient of advance $\mathrm{J}$ is varied from 0.3 to 0.7 . All the results obtained are discussed in terms of the non-dimensional parameters described as follows:

$J=\frac{V_{a}}{n D}$

$K_{T}=\frac{T}{\rho n^{2} D^{4}}$

$K_{Q}=\frac{Q}{\rho n^{2} D^{5}}$

$\eta_{\mathrm{o}}=\frac{J}{2 \pi} \frac{K_{T}}{K_{Q}}$

Where $\rho$ is the fluid density, $n$ the propeller rotational speed, $D$ the diameter of propeller, $V_{a}$ the flow velocity, $K_{T}$ the thrust coefficient and $K_{Q}$ the torque coefficient of the propeller.
The mean $\mathrm{Y}^{+}$on the blade surfaces for the present case is less than 300 . This is an accordance with the logarithmic law for mean velocity $30<\mathrm{Y}^{+}<300$.

Table 3 summarizes the obtained results using different meshes. The analyses of the results shows clearly that the mesh 02 is the more appropriate and is taken in all subsequent calculations.

Table 3.Mesh sensitivity analysis of $\mathrm{B} 5-75$ for $\mathrm{J}=0.6$

\begin{tabular}{|c|c|c|}
\hline & $\mathrm{K}_{\mathrm{T}}$ & $10 \mathrm{~K}_{\mathrm{Q}}$ \\
\hline Mesh 01 & $0.128(6.56 \%)$ & $0.203(7.72 \%)$ \\
\hline Mesh 02 & $0.145(5.83 \%)$ & $0.207(5.90 \%)$ \\
\hline Mesh 03 & $0.145(5.83 \%)$ & $0.203(7.72 \%)$ \\
\hline Mesh 04 & $0.126(8.02 \%)$ & $0.207(5.90 \%)$ \\
\hline EXP & 0.137 & 0.220 \\
\hline
\end{tabular}

The table 4 shows the comparison between present computational results and the B5-75 experimental results [7]. It is clearly seen that the computational trust coefficient $\mathrm{K}_{\mathrm{T}}$ and the torque coefficient $\mathrm{K}_{\mathrm{Q}}$ agree well with the experimental results. The maximum relative error is $7.52 \%$ for the trust coefficient and the $5.66 \%$ for the Torque coefficient.

Table 4.Open water characteristic for B 5-75

\begin{tabular}{|c|c|c|c|c|c|c|}
\hline $\mathrm{J}$ & $\begin{array}{c}\mathrm{K}_{\mathrm{T}} \\
\text { EXP }\end{array}$ & KT RANS & Error & $\begin{array}{c}10 \mathrm{~K}_{\mathrm{Q}} \\
\text { EXP }\end{array}$ & $\begin{array}{c}10 \mathrm{~K}_{\mathrm{Q}} \\
\text { RANS }\end{array}$ & Error \\
\hline 0.3 & 0.266 & 0.265 & $0.37 \%$ & 0.353 & 0.355 & $5.66 \%$ \\
\hline 0.4 & 0.229 & 0.245 & $6.98 \%$ & 0.312 & 0.330 & $5.76 \%$ \\
\hline 0.5 & 0.186 & 0.200 & $7.52 \%$ & 0.263 & 0.286 & $8.04 \%$ \\
\hline 0.6 & 0.137 & 0.145 & $5.83 \%$ & 0.220 & 0.225 & $2.27 \%$ \\
\hline 0.7 & 0.081 & 0.075 & $7.40 \%$ & 0.163 & 0.160 & $1.8 \%$ \\
\hline
\end{tabular}

The open water characteristic results of the three tested propellers are shown in figure 4.

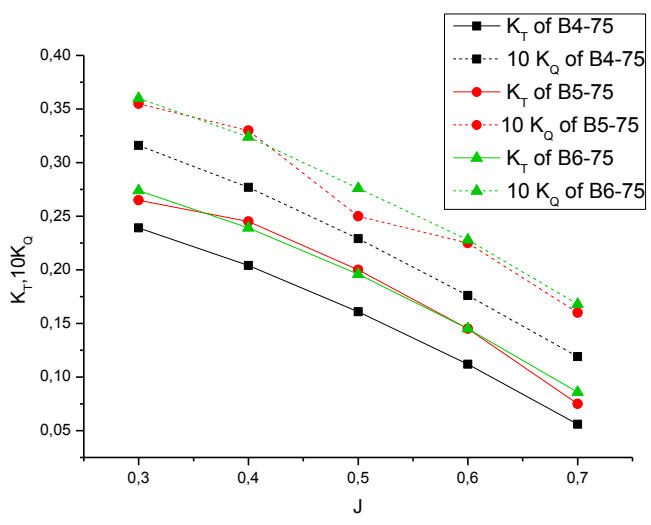

Fig. 4.Open water characteristics.

It appears from the values of $\mathrm{K}_{\mathrm{T}}$, the propellers $\mathrm{B} 5-75$ and B6-75 have better performance. However the behavior of these propeller is not the same for the lower and higher advance coefficient. Concerning the torque coefficient the trend is almost similar for the three propellers.

Figure 5 presents the propeller efficiency for the three tested cases function of advance coefficient $\mathrm{J}$. 


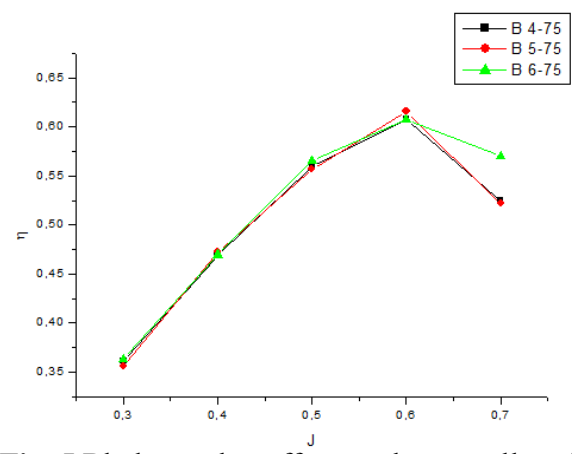

Fig. 5.Blade number effect on the propeller efficiency

The numerical result shows that the number of blades has an influence on the open water performances of marine propellers. It is clearly seen that the efficiency increases with the rise of the $J$ up to 0.6 , then it decreases for all the tested propellers. It has to be noted that the efficiency value for B6-75 is the highest one.

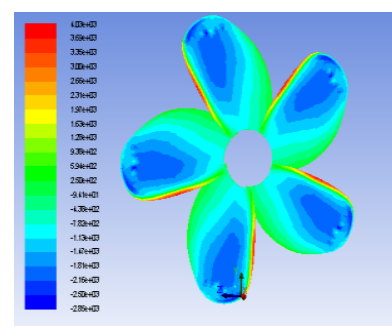

Suction side

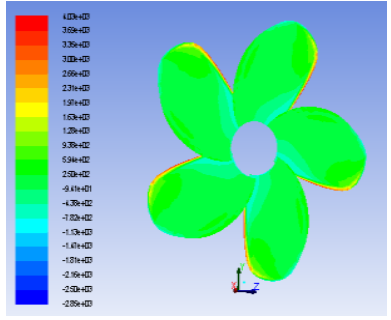

Pressure side
Fig. 6..Pressure contour for $\mathrm{J}=0.5$

Figure 6 shows the pressure contours on the suction and pressure sides of the propeller blades for the advance coefficient $\mathrm{J}=0.6$. It is observed a lower pressure zone near the tip of the blade which is a possible source of cavitation. On the pressure side near the leading edge a large pressure zone is observed.

\section{Conclusion}

In the present study, the effect of the blade number characteristics on the propeller hydrodynamic performances is numerically studied. The code Fluent is used to solve the averaged Navier-stokes equation. The K- $\omega$ model has been selected. Three grids with different meshes qualities have been tested. The B5-75 propeller, has been chosen for the validation of the numerical model. The obtained results provide good agreement with the available experimental data and show that the blades number effect considerably the marine propellers performances. They also show that the six blades propeller is the best adapted one for the open water flows.

\section{References}

1. R.Arazgaldi, A.Hajilouy, B.Farhanieh. Experimental and numerical Investigation of marine propeller cavitation. Journal of Scientia Iranica. Sharif University of Technology 16, 6. pp. 525-533(2009).
2. V.Krasilnikov, Jiaying Sun, Karl Henning Halse. CFD Investigation in Scale Effect on Propellers with Different Magnitude of Skew in Turbulent Flow, First International Symposium on Marine Propulsorssmp, Trondheim, Norway, (2009)

3. T.Watanabe, T.Kawamura, Y.Takekoshi, M.Maeda and S. H. Rhee. Simulation of steady and unsteady cavitation on a marine propeller using a RANS CFD code. Presented at the Fifth International Symposium on Cavitation, Japan.( 2003)

4. S.E.Belhenniche, M.Aounallah, O.Imine, F.Çelik. Effect of geometric configurations on hydrodynamic performance assessment of a marine propeller, Brodogradnja/Shipbuilding (2016).

5. H.Ghassemi. The effect of wake flow and skew angle on the ship propeller performance. transaction B: Mechanical Engineering Vol. 16, No. 2, pp. 149-158, Sharif University of Technology, Iran.( 2009)

6. E.BENINI. Multiobjective Design Optimization of B-Screw Series Propellers Using Evolutionary Algorithms, Marine Technology and SNAME News, Vol.40, No. 4, p. 229-238 (2003).

7. T. Muszyński, P.Strzelczyk, Experimental Investigation of A Variable Geometry Ducted Propeller. Advances in Science and Technology Research Journal 7, 17, (2013). pp. 56-61

8. M.Bennaya, J. Gong, M.Hegaze, W.Zhang. Numerical simulation of marine propeller hydrodynamic performance in uniform inflow with different turbulence models, Applied Mechanics and Materials, 1019-1025 (2013).

9. D.Boucetta, O.Imine.Numerical simulation of the flow around marine propeller series, Journal Of Physical Science And Application, 55-61 (2016).

10. Chao Wang, S. Huang, X. Chang, M. He. Applying periodic boundary conditions to predict open water propeller performance, Journal of marine Science and applications, (9) 262-267.( 2010)

11. S.E. Belhenniche, M. Aounallah, O. Imine, F. Çelik 2012. Application of CFD in Analysis of Steady and Unsteady turbulent flow Past a Marine Propeller, International Conference of Heat and Mass Transfer ICHMT Palermo (Italy).

12. D.C.Wilcox.Turbulence Modeling for CFD, 2nd Ed., DCW Industries, Inc., La Canada CA,1998.

13. B. E. Launder and D. B. Spalding, The Numerical Computation of Turbulent Flows. Computer Methods in Applied Mechanics and Engineering, 3:269-289, (1974). 